\title{
Percepção de adolescentes acerca de suas atividades de vida, trabalho e lazer
}

\author{
Adolescents' perceptions of their living, working and playing activities \\ Percepción de adolescentes sobre sus actividades de vida, trabajo y ocio
}

\author{
Eveline Pinheiro Beserra ${ }^{\text {I }}$ Leilane Barbosa de Sousa ${ }^{I I} ;$ Maria Dalva Santos Alves ${ }^{I I I}$; Fabiane do Amaral Gubert ${ }^{I V}$
}

\begin{abstract}
RESUMO: Objetivou-se analisar a percepção de adolescentes acerca de suas atividades de vida, trabalho e lazer. Trata-se de pesquisa-ação desenvolvida em uma escola localizada na periferia de Fortaleza, Ceará, em 2011. Foram selecionados 25 adolescentes que responderam a um questionário, em entrevista, e participaram de uma oficina educativa, ambos abordando suas atividades cotidianas. Os resultados evidenciaram que os participantes convivem com a realidade do trabalho infantil, sem amparo legal e em situação de exploração. A busca pelo trabalho é motivada pela necessidade financeira de se manter e de auxiliar a família. As atividades de lazer concentram-se em festas noturnas e práticas esportivas de risco. Após a intervenção, os participantes reconheceram a importância do investimento profissional seguro e de atividades de lazer que não os exponham a riscos. Conclui-se que o uso do Modelo de Atividade de Vida permite a discussão e a reflexão dos adolescentes sobre trabalho, lazer e estudo.
\end{abstract}

Palavras-Chave: Enfermagem; adolescência; educação em saúde; modelos de enfermagem.

\begin{abstract}
This action research study, to examine adolescents' perceptions of their living, working and playing activities, was carried out at a school on the periphery of Fortaleza, Ceará, Brazil. The 25 adolescents selected answered an interview questionnaire and participated in an educational workshop, both addressing their everyday activities. The results showed that child labor, without legal support and in situations of exploitation, is a reality in the participants' lives. Work is sought to meet the financial needs of supporting themselves and helping the family. Leisure activities consist primarily of night parties and extreme sports. After the intervention, the participants recognized the importance of safe professional investment and leisure activities that do not expose them to risk. It was concluded that the use of Models of Activities of Living enables teenagers to think and talk about work, leisure and study. Keywords: nursing; adolescent; health education; nursing models.
\end{abstract}

RESUMEN: El objetivo fue analizar la percepción de adolescentes sobre sus actividades de vida, trabajo y ocio. Se trata de investigación-acción desarrollada en una escuela de la periferia de Fortaleza, Ceará, Brasil, en 2011. Fueron seleccionados 25 adolescentes que respondieron a un cuestionario, en entrevista, y participaron de un taller educativo, ambos abordando sus actividades diarias. Los resultados señalaron que los participantes conviven con la realidad del trabajo infantil, sin amparo legal y en situación de explotación. La búsqueda de trabajo está motivada por la necesidad económica de mantenerse y ayudar a la familia. Las actividades de ocio se concentran en fiestas nocturnas y prácticas deportivas de riesgo. Después de la intervención, los participantes reconocieron la importancia de una inversión profesional segura y de actividades de ocio que no los expongan a riesgos. En conclusión, el uso del Modelo de Actividad de Vida permite la discusión y la reflexión de los adolescentes sobre el trabajo, el ocio y el estudio.

Palabras Clave: Enfermería; adolescencia; educación en salud; modelos de enfermería.

\section{INTRODUÇÃO}

Trabalho é uma atividade remunerada e o lazer fora do momento do trabalho é uma necessidade humana básica complementar a essa atividade ${ }^{1}$. O lazer pode ser compreendido como um conjunto de atividades, após as obrigações profissionais, familiares e sociais, em que a pessoa pode se entregar de livre vontade, seja para descanso seja para recreação ${ }^{2}$.

Em estudo realizado com trinta adolescentes, que analisou o significado do trabalho para esse grupo, observou-se que estes o percebem como uma forma de fugir da sua condição social, de ter dinheiro para pagar suas despesas e, também, alguns gastos da família, porém identificou uma conotação negativa, como prejudicar os estudos, não ser valorizado pelos outros, além de prevalecer a tentativa de conciliar uma dupla jornada de estudo e trabalho ${ }^{3}$.

A inserção do adolescente no mercado de trabalho é tema controverso e polêmico, pois há divergên-

\footnotetext{
'Enfermeira. Doutora em Enfermagem. Professora da Universidade Federal do Ceará. Fortaleza, Brasil. E-mail: eve pinheiro@yahoo.com.br. IIEnfermeira. Doutora em Enfermagem. Professora da Universidade da Integração Internacional da Lusofonia Afrobrasileira. Redenção, Ceará, Brasil. E-mail: leilane@unilab.edu.br.

IIIEnfermeira. Doutora em Enfermagem. Professora da Universidade Federal do Ceará. Fortaleza, Brasil. E-mail: dalvaalves06@uol.com.br.

IVEnfermeira. Doutora em Enfermagem. Professora da Universidade Federal do Ceará. Fortaleza, Brasil. E-mail: fabianegubert@hotmail.com.
} 
cias na literatura sobre os efeitos do trabalho irregular em seu desenvolvimento, principalmente quando em condições insalubres e sem fiscalização e normatização legal ${ }^{4}$. Esse processo deveria ser subsidiado pelo respaldo legal e adequação do ambiente às necessidades e realidade dos adolescentes. Em relação ao lazer, verifica-se que, entre eles, prevalece o interesse por atividades direcionadas à música, à televisão, aos passeios com amigos, aos esportes, à igreja e aos bares ${ }^{5}$.

trabalho na adolescência, exceto na condição de menor aprendiz, muitas vezes, pode ser motivo de abandono no estudo, o que ocasiona problemas sociais futuros por falta de qualificação. Já o lazer entre jovens pode os colocar em condição de vulnerabilidade como início da vida sexual precoce, exposição ao álcool e outras drogas, riscos da prática de esportes radicais, entre outros. Diante disto, a pesquisa teve como objetivo analisar a percepção de adolescentes acerca de suas atividades de vida, trabalho e lazer.

\section{Referencial Teórico-Metodológico}

O estudo teve como referencial teórico o Modelo de Vida ${ }^{1}$. Importante destacar que o Modelo de Vida é composto por 12 atividades. No presente artigo, optou-se por expor os resultados que contemplam as atividades de vida - trabalhar e distrair-se. Este artigo é oriundo da tese de doutorado intitulada Saúde do adolescente: ação educativa mediada pelo modelo de atividades de vida, defendida no ano de 2012, no Programa de Pós-Graduação em Enfermagem da Universidade Federal do Ceará.

Trata-se de um estudo de abordagem qualitativa, realizado numa escola, situada no bairro Pirambu, em Fortaleza-Ceará, Brasil, que utilizou a pesquisa-ação ${ }^{6}$. Esse bairro é situado na periferia, numa comunidade pobre, onde o trabalho informal entre os adolescentes é uma realidade. $\mathrm{O}$ período de pesquisa ocorreu de abril a junho de 2011.

Os critérios de inclusão dos participantes do estudo foram: estudar à noite, não ser beneficiado com as ações de promoção da saúde pela estratégia da saúde da família e possuir entre 10 e 18 anos de idade. Assim, foram selecionados 25 participantes, com idade entre 15 e 18 anos. A seleção dos sujeitos foi aleatória. Os jovens foram convidados a participar e os 25 primeiros que trouxeram os Termos de Consentimento Livre e Esclarecido assinados por eles e seus responsáveis fizeram parte do estudo.

A coleta de dados ocorreu em dois momentos: no primeiro, foi realizada uma entrevista que questionava as atividades de vida dos adolescentes, gerando informações que subsidiaram a elaboração das oficinas educativas, contextualizadas à realidade dos participantes, as quais constituíram o segundo momento do estudo. Na oficina sobre as atividades de vida - trabalhar e divertir-se -, utilizaram-se três vídeos, cujos conteúdos desencadearam a discussão. $\bigcirc$ primeiro tratava de uma reportagem sobre as atividades de lazer nas férias, promovidas pela prefeitura de uma cidade brasileira. $\mathrm{O}$ encontro visou esclarecer a importância do lazer na vida do adolescente, iniciando o debate quanto à escolha do tipo de entretenimento. $\mathrm{O}$ segundo retratava uma reportagem de um adolescente trabalhando, na condição de jovem aprendiz, com situação de trabalho regularizada, sem prejudicar os estudos. $O$ terceiro explorava o trabalho infantil. A coleta dos dados na oficina aconteceu por meio da observação participante e filmagem.

Para tratamento dos dados, foram utilizadas as práticas discursivas, que constituem técnicas de análise dos próprios repertórios e suas interpretações, associando termos e descrições, para deixar aflorar seus sentidos em categorias, classificações e tematizações? As categorias do estudo foram: Diálogos sobre lazer e Diálogos sobre trabalho.

Foram respeitados os aspectos legais e éticos que envolvem pesquisas com seres humanos, conforme a Resolução n ${ }^{\circ}$ 196/96. O estudo foi aprovado pelo Comitê de Ética em Pesquisa da Universidade Federal do Ceará, sob protocolo de número 038/11. Para manter o anonimato dos adolescentes, nomeou-se cada entrevistado com a letra $(E)$ e um número cardinal sequencial.

\section{Resultados e Discussão}

A difícil condição financeira traz o risco social. Então, foram criados programas esportivos, culturais e trabalhos orientados, destinados, principalmente, aos moradores dos bairros periféricos, com o objetivo de exercer controle social do tempo livre, mas muitos jovens não interagem com essas atividades ou não são por elas motivados ${ }^{8}$.

A oficina sobre as atividades de lazer e trabalho evidenciou a dinâmica dos adolescentes sobre atividade laboral e práticas de relaxamento e distração. $\mathrm{O}$ trabalho na adolescência é, muitas vezes, acometido pela necessidade econômica, já o lazer dos adolescentes não aparece da mesma forma para todos ${ }^{4,9}$.

\section{Diálogos sobre lazer}

Inicialmente, foi abordada a atividade de vida lazer. Os recursos da informática e esportes foram percebidos como meios de lazer pelos adolescentes do estudo, conforme verificado a seguir:

Eu acho assim... seria mais uma lan house, computador e videogame. Porque fazer esporte é meio difícil. Isso é geral tanto para meninas quanto para meninos. (E1)

Geralmente, os rapazes gostam de jogar bola. São poucos os que não gostam de futebol. (E5)

O videogame é uma ferramenta capaz de aperfeiçoar as habilidades cognitivas e perceptivas, porém 
podem ocorrer repercussões negativas naqueles jogos com teor de violência ${ }^{10}$. Outra realidade dos adolescentes é o meio virtual, no qual há um aumento da frequência dos adolescentes no uso excessivo da internet, sendo visíveis os déficits de comportamento em suas rotinas ${ }^{11}$. Observou-se que, mesmo apreciando esportes convencionais, os adolescentes parecem não ter acesso pleno a este meio de lazer. Em estudo com adolescentes de duas cidades brasileiras sobre as possíveis associações das atividades físicas com o lazer, constatou-se a prevalência de inatividade física ${ }^{12}$, que favorece riscos cardiovasculares futuros.

Na discussão sobre lazer, emergiu a palavra emoção, representada pelos esportes radicais.

Depende do grau de risco [...] alguns têm sangue radical mesmo, fazem esportes muito perigosos, como se arriscar em cachoeira, pular de penhasco. Na cidade, é mais racha, dependendo do perfil do jovem. Racha é crime, pois arrisca sua vida e de outras pessoas. (E1)

Na percepção desses adolescentes, os motivos que levam os jovens a essas práticas são a busca de emoção e a influência de amigos, cujas repercussões na vida juvenil são itens importantes a considerar, pois a necessidade de aceitação no grupo pode implicar vulnerabilidades, como arriscar a própria vida e a saúde. Verifica-se que a aprovação dos amigos diante de suas condutas é um fator que influencia muito o modo adolescer de viver ${ }^{13}$.

Nos diálogos, percebeu-se ainda que a falta de opções de lazer os coloca na rua e, consequentemente, vulneráveis às circunstâncias de marginalidade. Essa realidade pode ser identificada no depoimento a seguir:

Eu assisti a uma reportagem sobre jovens que praticaram um roubo e foram parar em uma delegacia... foi comprovado que nenhum estava drogado. Eu acho que se houvesse mais lazer tinha evitado essa besteira. Teria como se ocupar mais. (E1)

Isto reflete a necessidade de mais lazer para os jovens, pois as atividades são pontualmente estimuladas; exercícios físicos e mais atividades de distração que favoreçam o desenvolvimento de habilidades e atitudes. Em estudo realizado com jovens de São Paulo, observou-se que a segregação socioambiental produz diferentes consequências negativas, tais como: menor acesso a serviços essenciais, maior exposição a riscos de saúde, maior propensão à violência e menores chances de mobilidade social ${ }^{14}$. Logo, espaços de lazer e serviços essenciais à promoção da saúde dos jovens favorecem um adolescer saudável, menos propenso à marginalização. Houve discussão sobre festas noturnas como lazer para os adolescentes. Essa prática acontece cada vez mais cedo, pois os pais permitem que os filhos menores de idade passem as madrugadas na companhia de outros menores.

Os jovens saem para festas para se divertir (E7).
Eu tiro por mim porque tanto faz: mulher, homem ou rapaz; [...] é bom se divertir por um lado, mas em festa tem como você se afundar. [...] Ali já aconteceu de várias [meninas] serem estupradas, dão bebida para eles fazerem o que querem. Se deixar... só tem aquele caminho de ida não tem o de volta. (E10)

As festas noturnas demonstram risco iminente para o adolescente, especialmente quando envolve o uso indiscriminado de drogas e da sexualidade, sendo item necessário de discussão na vida do jovem ${ }^{15}$. Essa realidade também ocorre em outras metrópoles; um exemplo é a cidade de Estocolmo, na Suécia, onde se percebe a acentuada incidência de violência e o consumo excessivo de álcool entre adolescentes, nas noites, principalmente, em festas e restaurantes ${ }^{16}$.

O comentário seguinte exemplifica que, nas festas noturnas, acontecem as paqueras, podendo ocorrer, posteriormente, relações sexuais.

Tem risco de conhecer uma pessoa na balada, porque quem vê cara não vê coração [...]. Porque há vários que estão ali na maldade, que querem te levar para algum canto. (E5)

Em estudo realizado em Chicago, com 1656 adolescentes, verificou-se que cerca de $20 \%$ dos participantes encontraram seu parceiro sexual mais recente na rua ou em locais públicos, principalmente em festas noturnas ${ }^{17}$.

A sexualidade na adolescência encontra-se vigorosa, precisando de orientação e instrução sobre hábitos saudáveis para o equilíbrio do desenvolvimento humano com valorização do autocuidado e do uso do preservativo de forma correta.

Ainda tomando o lazer como item de discussão, procurou-se aqui relacioná-lo com a violência. Tornou-se constante a violência urbana no cotidiano dos brasileiros, gerando um grande número de vítimas, entre estas, adolescentes, cujas sequelas físicas e emocionais constituem um problema de saúde pública ${ }^{18}$.

Agora nosso lazer está todo dominado pelo crime. Se você for para uma praça, você é roubado, pode ter tiro. Você não pode ir à festa porque há briga, drogas. Daqui a pouco você não vai poder nem ficar dentro de casa. (E1)

Se vai a uma pizzaria, há risco de ser assaltado. Chegam, é um assalto... e se não matam todos que estiverem à mesa. (E5)

A violência, na visão desses jovens, é algo real e relacionado com as práticas de lazer, pois destacam que em qualquer lugar há perigo de assalto ou de sofrer alguma lesão. Isto priva o jovem de desempenhar algumas práticas, bem como o situa em vulnerabilidade física e emocional.

[...] chegou um cara pegando no meu ombro como se fosse um amigo meu, passa o celular, e eu só fiz entregar. (E2) 
Eu fui assaltada no primeiro dia de aula, no portão do colégio. Quase que eu nem vinha mais à aula. (E4)

Esses dois últimos depoimentos mostram a realidade de um grande centro urbano, em que a criminalidade toma grandes proporções e impede os jovens de fazer atividades livres, pois há risco de ser assaltado ou de sofrer lesão física. Percebem o lazer de forma limitada, tanto pela falta de oportunidade como pelo risco de violência.

\section{Diálogos sobre trabalho}

No segundo momento da oficina, os diálogos focalizaram o trabalho. Trabalhar é proibido para adolescentes de 10 a 13 anos e, entre 14 e 15 anos, é admitido o trabalho na condição de aprendiz ${ }^{19}$.

Motivados pelo vídeo, os adolescentes afirmaram que trabalham para ser independentes financeiramente e por necessidade. Numa discussão sobre a escolha do trabalho do jovem, a maioria afirmou que ele se ocupa em atividades que não seriam de sua escolha.

[... ] a gente quer uma coisa e a mãe da gente não pode, aí fica na cabeça - eu vou atrás de um trabalho. Eu trabalho há cinco anos, coloquei isso na minha cabeça, depois que eu tive meu filho pensei assim... Comecei a trabalhar na feira, ganho 320 por mês, mas por obrigação, porque por mim eu ficava em casa assistindo televisão. Aí, hoje, faz duas semanas que eu entrei numa fábrica de calcinha, sou costureira e ganho 555 reais por mês. (E5)

Nota-se que a motivação por ganhar dinheiro se torna maior do que a escolha de atividades que proporcionem prazer. Em estudo realizado no interior de São Paulo, com adolescentes, também foi observado que eles estão trabalhando para garantir uma renda básica para a sobrevivência, bem como para adquirir bens materiais dos seus interesses ${ }^{20}$.

$\mathrm{Na}$ condição por último relatada, percebe-se que o adolescente começou a trabalhar com 10 anos, numa situação de risco, na rua, como feirante, e sem apoio legal, ainda continua num ofício informal sem garantias e sem especular uma segurança futura.

Ao serem questionados sobre profissão, todos argumentaram que se sentem forçados, pela situação em que vivem, a procurar um emprego. No grupo, havia jovens que começaram a trabalhar após a entrevista ou mudaram de emprego, demostrando a instabilidade de sua ocupação.

Diante do exposto, emergiu o questionamento: $\mathrm{O}$ que vocês querem ser daqui a um ano? Obteve-se como resposta:

Dizem que os jovens têm aquela coisa de constantemente querer mudar de profissão... eu estou com quatro: turismo, telemarketing, auxiliar de administração e culinária. Dois desses eu já fiz. Só que agora eu tenho que me arriscar a trabalhar em alguma coisa que en não estava pensando, vendedor... tenho que primeiro trabalhar com isso para seguir meu sonho. (E1)

As atividades educativas devem ser provocativas para o jovem, pois a reflexão sobre sua realidade favorece mudanças e revisão de suas condutas. Com efeito, é importante provocar o desafio de pensar sobre o futuro desses jovens que vivem em contextos vulneráveis ${ }^{21}$.

\begin{abstract}
Não estamos trabalhando obrigatoriamente para pegar nosso dinheiro e dizer é meu, para ter nossa independência. Possuem cinco filhos, só uma pessoa trabalha... vou ajudar meu pai e minha mãe, colocar comida em casa, mas não vou esquecer do meu sonho. Guardar um pouquinho de dinheiro para futuramente ser apostado em seu sonho. (E3)
\end{abstract}

Os jovens têm seus sonhos, mas também necessidades imediatas. Alguns adolescentes privam-se de seus sonhos, pois, muitas vezes, precocemente, geram uma família ou entram no mundo das drogas e da criminalidade, achando que, por esse caminho, será mais fácil alcançar o que almejam, porém isto é reflexo da desigualdade social na periferia. A maioria das pessoas que mora na periferia sofre com as implicações da questão social do trabalho, da reprodução social, das desigualdades sociais e da pobreza ${ }^{22}$.

Na discussão, também emergiu a percepção deles relativa à exploração, pois, muitas vezes, trabalham de maneira informal, sem amparo legal, motivados pela necessidade financeira; permanecem nele, mesmo percebendo que este exige muito esforço.

Já pensei em passar uma semana em casa [...] o patrão vem buscar, porque ele quer que eu trabalhe para enriquecê-lo, me quer como escrava; as costureiras mal tem tempo para almoçar, só 40 minutos para ir em casa correndo almoçar. [...] o dinheiro é só para entregar, quando eu fico com dinheiro, [são] 10 reais no bolso. (E5)

trabalho na adolescência é visto como mão de obra barata, sem compromisso trabalhista, sendo percebido como uma excelente opção para o empregador. No contexto em que os adolescentes vivem, muitas vezes eles se veem obrigados a trabalhar. Eles mencionaram que precisam ajudar em casa com as despesas e comprar objetos de seu interesse.

Os adolescentes pensam que a liberdade de ter dinheiro para pagar suas despesas, e também algumas de sua família, leva a ter um sentimento diferenciado, por meio do qual eles passam a se sentir mais úteis. Há, também, a percepção de que o adolescente deve conciliar a dupla jornada de trabalho e estudo ${ }^{3}$.

Outro vídeo problematizante mostrou o trabalho infantil expressando a exploração e a ilegalidade desse ato. Existiu a afirmativa: Para mim, se a criança está trabalhando e estudando para mim não é crime. No contexto deles, é normal uma criança de dez anos trabalhar para ajudar a família. Um estudo com participantes de 6 a 
16 anos corrobora com os comentários dos participantes deste estudo, que retratam que o trabalho precoce não gera prejuízos no rendimento escolar ${ }^{20}$. Este estudo não avaliou se há ou não prejuízo, somente registrou as percepções dos jovens sobre as temáticas dialogadas.

$\mathrm{O}$ vídeo seguinte retratava o abuso sexual por meio de reportagens comumente transmitidas pela mídia, uma vez que a exploração sexual é crescente em todo o mundo ${ }^{23}$. No Brasil, há o enfoque da situação de marginalização social e econômica, contudo não justifica o conceito multifacetado dessa realidade. Logo, foi iniciada a discussão sobre prostituição:

Há perto lá de casa meninas que trabalham com prostituição, uma de 15 e outra maior. A maior iniciou por incentivo de uma amiga, as duas estavam sem dinheiro. [...] Já a de 15, aos 13, foi molestada pelo tio dela. Isso ficou na cabeça dela, acho que ela gostou, não sei, aí ficou na prostituição. (E8)

A fala desse adolescente retrata aspectos da prostituição já revelados em estudos, como forma fácil de obter dinheiro e sustentar-se. Em pesquisa realizada com adolescentes prostitutas, verificou-se que, no vínculo familiar, não só há violência física e sexual, como violência psicológica, propiciando um desenvolvimento inadequado ${ }^{24}$. Em estudo com adolescentes prostitutas em Israel, também foi verificado o abuso sexual anterior e a vitimização sexual comercial ${ }^{25}$.

Tem uma menina perto lá de casa que vivia nessa vida, ela diz que se não tivesse vivido isso não sabia nem se estava viva. Hoje ela tem a casa dela, os filhos, nessa vida ela conseguiu até um marido, que não vive com ela, mas a mantém [...]. (E10)

Tenho uma amiga que morava no morro, hoje, ela mora na Itália. De um programa que fez, ele gostou muito dela e perguntou se ela queria ir embora com ele. Hoje, ela é uma senhora. Não tem quem diga que ela fez programa, está mais para atriz de novela. (E7)

Houve também a percepção da prostituição como uma oportunidade, diante da possibilidade de encontrar um marido que proporcione conforto. Em estudo com adolescentes prostitutas, observou-se que a prostituição não é encarada como profissão, mas que tem caráter de atividade temporária, pois há insatisfação e desejo de mudar de vida ${ }^{24}$.

A prostituição também foi exemplificada, por uma adolescente do grupo, como situação corriqueira. Relatou ter amigas que faziam programa tanto com brasileiros como com estrangeiros. Citaram também o exercício da prostituição para alimentar o vício por drogas ilícitas.

Eu já disse semana passada: tu não tens vergonha nessa cara não, dá por uma pratada de pó?! Aí ela respondeu: 'a gente cheira e ao mesmo tempo...'. (E5)

O consumo de drogas lícitas e ilícitas por prostitutas é diário, sendo fator de risco para contaminação por Vírus da Imunodeficiência Humana e Síndrome da
Imunodeficiência Adquirida ${ }^{26}$. É importante conscientizar os jovens sobre as repercussões da prostituição, pois implica traumas em diferentes esferas do ser social, psicológico e físico. Assim, é indispensável que os profissionais de saúde estejam conscientes do seu papel de educador compromissado com a transformação da realidade, visando à superação das vulnerabilidades ${ }^{27}$.

Antes da avaliação do conteúdo apreendido, houve reflexão acerca do trabalho do adolescente que não deve colocar sua vida em risco, mas preservar sua integridade psicofísica. Também foi discutida a questão da educação, como direito de cidadania. A enfermagem pode levá-los à reflexão, colaborando para a promoção da saúde e desenvolvimento de habilidades pessoais. É preciso compreender a construção da prática educativa com adolescente de forma ativa, o que necessita de reflexões revividas e redimensionadas para viabilizar novas práticas de educação em saúde, considerando a apreensão do sujeito ${ }^{28}$.

\section{Conclusão}

Concluiu-se que o uso do Modelo de Vida favoreceu a discussão e reflexão dos adolescentes sobre trabalho, lazer e a importância do estudo. A enfermagem, em suas ações educativas, deve favorecer ao jovem a reflexão sobre as diferentes vivências, a fim de levá-los ao pensamento crítico e posicionamento positivo ante os riscos e vulnerabilidades do adolescer, para serem agentes de mudança de sua história de vida.

As percepções de lazer e trabalho dos adolescentes permitiram identificar sua realidade e dialogar de acordo com suas crenças e linguagem, que retratam suas vivências. Notou-se que existem lazeres que os colocam vulneráveis ao álcool, drogas, violência e prostituição. Já o trabalho foi percebido por eles como uma prática que não intervém nos estudos, até porque muitos precisam trabalhar para ajudar no sustento da família; logo, uma necessidade imediata.

Como limitação do estudo, atenta-se para o número restrito de alunos e somente em uma escola, indicando a necessidade investigar amostra representativa do universo. Para aprofundar a investigação do fenômeno, propõe-se estudo comparativo de adolescentes de diferentes segmentos socioeconômicos.

\section{REFERÊNCIAS}

1.Roper N, Logan W, Tierney AJ. O modelo de enfermagem: baseado nas atividades de vida diária. Lisboa $(\mathrm{Pt})$ : Climepsi; 2001.

2.Dumazedier J. Lazer e cultura popular. São Paulo: Perspectiva; 2004.

3.Rizzo CBS, Chamon EMQO. O sentido do trabalho para o adolescente trabalhador. Trab educ saúde. 2010; 8:407-17. 4.Silva RDM, Trindade ZA. Adolescentes aprendizes: 
aspectos da inserção profissional e mudanças na percepção de si. Rev bras orientac prof. 2013; 14:73-86.

5.Pratta EMM, Santos MA. Uso de drogas na família e avaliação do relacionamento com os pais segundo adolescentes do ensino médio. Psico. 2009; 40:32-41.

6.Grittem L, Meier MJ, Zagonel IPS. Pesquisa-ação: uma alternativa metodológica para pesquisa em enfermagem. Texto contexto - enferm. 2008; 17:765-70.

7.Spink MJ. Práticas discursivas e produção de sentido no cotidiano: aproximações teóricas e metodológicas. São Paulo: Cortez; 2004.

8.Eduardo LP, Egry EY. Estatuto da Criança e do Adolescente: a visão dos trabalhadores sobre sua prática. Rev esc enferm USP. 2010; 44:8-24.

9.Pfeifer LI, Martins YD, Santos JLF. A influência socioeconômica e de gênero no lazer de adolescentes. Psicol teor pesqui. 2010; 26:427-32.

10.Alves L, Carvalho AM. Videogame: é do bem ou do mal? Como orientar pais. Psicol estud 2011; 16:251-8.

11.Barossi O, Meira SVE, Góes DS, Abreu CN. Programa de Orientação a Pais de Adolescentes Dependentes de Internet (PROPADI). Rev bras psiquiatr. 2009; 31:387-95. 12.Fernandes RA, Christofaro DGD, Dias RMR, Codogno JS, Oliveira AR Desnutrição e sua associação com atividades durante o lazer entre adolescentes. Ciênc saúde coletiva. 2014; 19:875-80.

13.Cardoso LRD, Malbergier A. A influência dos amigos no consumo de drogas entre adolescentes. Estud psicol. 2014; 31:65-74.

14.Borelli E. Vulnerabilidades sociais e juvenil nos mananciais da zona sul da cidade de São Paulo. Revista Katálysis. 2012; 15:62-9.

15.Valle TGM, Melchiori LE. Saúde e desenvolvimento humano. São Paulo: Cultura Acadêmica; 2010.

16.Ramstedt M, Leifman H, Müller D, Sundin E, Norström T. Reducing youth violence related to student parties: findings from a community intervention project in Stockholm. Drug Alcohol Rev. 2013; 32:561-5.

17.Staras SA, Maldonado-Molina MM, Livingston MDB, Komro KA. Association between sex partner meeting venues and sexual risk-taking among urban adolescents. J Adolesc Health. 2012; 51:566-71

18.Silva CJP, Ferreira EF, Paula, LPP, Naves MD, Vargas AMD, Zarzar PMPA. A violência urbana contra crianças e adolescentes em Belo Horizonte: uma história contada através dos traumas maxilofaciais. Physis. 2011; 21:1103-20. 19.Santos AS. Política Nacional de Saúde para a Erradicação do Trabalho Infantil e Proteção ao Adolescente Trabalhador: o desafio de construir a atenção integral à saúde de crianças e adolescentes trabalhadores no Sistema Único de Saúde. Boletim Epidemiológico Paulista [Online]. 2013; 10(114):5-16.

20.Lima MB, Ribeiro DF, Andrade AS. Percepções de crianças e adolescentes sobre seu trabalho informal. Psicol pesq. 2011; 17:48-66.

21.Freitas JD, Porto MF. Por uma epistemologia emancipatória da promoção da saúde. Trab educ saúde. 2011; 9:179-200.

22.Ivo ABL. A periferia em debate: questões teóricas e de pesquisa. Cad CRH. 2010; 23(58):9-15.

23. Moraes SP, Vitalle MSS. Sexual and reproductive rights in adolescence. Rev Assoc Med Bras. 2012; 58:48-52.

24.Moura ADA, Oliveira RMS, Lima GG, Farias LM, Feitosa AR. O comportamento de prostitutas em tempos de AIDS e outras doenças sexualmente transmissíveis: como estão se prevenindo? Texto contexto - enferm. 2010; 19:545-3.

25.Peled E, Lugasi R. How Israeli social workers perceive adolescent girls in prostitution. Child Abuse Negl. 2015; 42:20-9.

26.Figueiredo R, Peixoto M. Profissionais do sexo e vulnerabilidade. Bol Inst Saúde (Impr.). 2010; 12:196-201.

27.Penna LHG, Carinhanha JI, Martins VV, Lucido VA, Soares BY, Fernandes GS. Perspectivas de adolescentes abrigadas sobre os serviços de saúde no apoio à sua maternidade. Rev enferm UERJ. 2013; 21:162-7

28.Coelho MMF, Miranda KCL, Gomes AMT, Silveira LC. Condições de produção do discurso de enfermeiros na prática educativa com adolescentes. Rev enferm UERJ. 2015; 23:9-14. 